\title{
Investigation on Structural, Optical and Thermal Properties of Diphenyl Urea-An Organic Non-Linear Optical Crystal
}

\author{
Jaishree Damodharan1, Kanchana Gopinath², Kesavasamy Ramasamy ${ }^{3}$ \\ ${ }^{1}$ Department of Physics, Sri Ramakrishna Institute of Technology, Coimbatore, India \\ ${ }^{2}$ Department of Physics, Government Arts College, Coimbatore, India \\ ${ }^{3}$ Department of Physics, Sri Ramakrishna Engineering College, Coimbatore, India \\ Email: jaishree.damu@gmail.com, kanchanagopinath@gmail.com, kesav cbe@yahoo.co.in
}

Received 7 January 2015; accepted 23 January 2015; published 27 January 2015

Copyright (C) 2015 by authors and Scientific Research Publishing Inc.

This work is licensed under the Creative Commons Attribution International License (CC BY). http://creativecommons.org/licenses/by/4.0/

(c) (i) Open Access

\begin{abstract}
Organic non-linear optical crystal diphenyl urea with molecular formula $\mathrm{C}_{13} \mathrm{H}_{12} \mathrm{~N}_{2} \mathrm{O}$ was synthesized and grown successfully by slow evaporation solution growth technique. The single crystal X-ray diffraction (XRD) confirms that it crystallizes in orthorhombic crystal system with non-centrosymmetric space group Pna2 ${ }_{1}$. The various functional groups were identified qualitatively by Fourier transform-infra red (FT-IR) and FT-Raman techniques. The electron absorption spectrum was studied by UV-Vis spectrophotometer. Thermal behavior of the crystal was evidenced by thermogravimetric (TG) and differential scanning calorimetric (DSC) analyses. From DSC the melting point of the crystal is found to be $145^{\circ} \mathrm{C}$. The existence of second harmonic generation (SHG) signal was evidenced using Kurtz Perry powder test and the efficiency of the crystal was found to be 0.64 times that of the standard KDP crystal.
\end{abstract}

\section{Keywords}

Non-Linear Optical Crystal, Slow Evaporation Technique, Characterization

\section{Introduction}

The ideal material that could have potential applications in non-linear optical devices should possess a combination of large non-linear figure of merit for frequency conversion, high laser damage threshold, fast optical response time, wide phase matchable angle, architectural flexibility for molecular design and morphology, optical transparency and high mechanical strength [1]. Extensive studies have been made on the synthesis and crystal 
growth of non-linear optical (NLO) materials over the past decade because of their potential application in the field of telecommunication, optical signal processing and optical switching. Organic materials have been of particular interest because the NLO responses in this broad class of materials are microscopic in origin, offering an opportunity to use theoretical modelling coupled with synthetic flexibility to design and produce novel materials [2] [3]. The most popular non-linear optical materials used to generate the SHG signal so far have been inorganic bulk crystals with rather small second-order nonlinear optical susceptibilities, such as potassium dihydrogen phosphate (KDP), lithium triborate (LBO), $\beta$-barium borate (BBO), lithium niobate $\left(\mathrm{LiNbO}_{3}\right)$, potassium niobate $\left(\mathrm{KNbO}_{3}\right)$ etc., [4]. But due its lower SHG efficiency and laser damage threshold, materials scientist focused their attention on organic materials because they possess large second-order nonlinear optical susceptibilities due to delocalized $\pi$-electrons [5]. These crystals were composed of aromatic molecules with $\pi$ electron donor and acceptor substitutions. They normally exhibit intermolecular charge transfer and lead to the required property of non centrosymmetry and make them good frequency conversion material [6].

Diphenyl urea has a wide biological importance. It has been expected to be an excellent potential tyrosine phosphate inhibitor and sickle-cell anemia treatment drug. The structure of diphenyl urea was reported by Rajinikant et al. [7] but there are no reports available in the literature on the growth and characterizations of diphenyl urea. Not only in biological aspects, diphenyl urea can also be used as non-linear optical crystal for industrial purposes. Hence in the present article we have reported the material synthesis, growth and characterization of diphenyl urea by slow evaporation solution growth technique. The grown crystals have been subjected into structural, spectral, optical, thermal and SHG studies.

\section{Experimental}

\section{Synthesis and Growth}

Analar R grade samples of $1.07 \mathrm{~g}$ of phenylisocyanate, $0.94 \mathrm{~g}$ of aniline and $0.5 \mathrm{ml}$ of triethyl amine are used as the reactants. The precipitated diphenylurea was filtered off and repeatedly recrystallised from ethanol to enhance the degree of purity of the synthesized compound. The chemical structure is shown in Figure 1.

The photograph of the grown crystals was shown in Figure 2.

\section{Characterization Studies}

The grown crystals were subjected to single crystal X-ray diffraction using Enraf Nonius-CAD 4 diffractometer. FT-IR and FT-Raman spectra were recorded to confirm the presence of functional groups using Bruker: RFS 27<smiles>O=C(Nc1ccccc1)Nc1ccccc1</smiles>

1,3-Diphenyl Urea

\section{Figure 1. Chemical structure.}

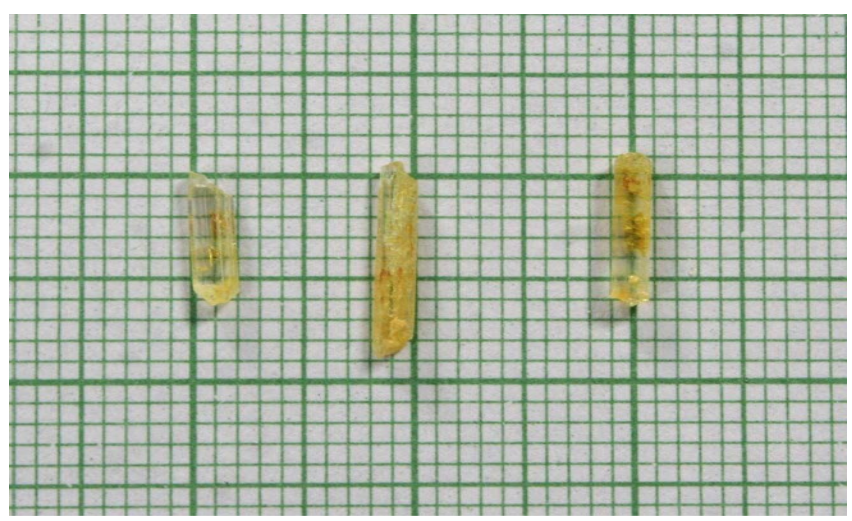

Figure 2. Photograph of diphenyl urea crystals. 
spectrometer in the frequency range $400-4000 \mathrm{~cm}^{-1}$. The optical absorption spectrum was recorded by double beam UV-Vis spectrophotometer. Thermal stability of the crystals was tested in the temperature range $0^{\circ}$ to $800^{\circ} \mathrm{C}$ using NETZSCH STA 409C. The NLO property of the crystal was confirmed by Nd-YAG laser using Kurtz Perry powder test.

\section{Results and Discussion}

\subsection{Single Crystal X-Ray Diffraction Analysis}

The single crystal XRD analysis of the grown crystal was carried out using Enraf Nonius-CAD 4 single crystal diffractometer. This study reveals that the crystal belongs to orthorhombic crystal system and crystallizes under non-centrosymmetric space group Pna2 ${ }_{1}$ with molecularformula $\mathrm{C}_{13} \mathrm{H}_{12} \mathrm{~N}_{2} \mathrm{O}$. The obtained lattice parameters are $\mathrm{a}=9.11 \AA, \mathrm{b}=10.56 \AA, \mathrm{c}=11.78 \AA$ and its volume is found to be $1133 \AA$ which are in close agreement with the reported values [7].

\subsection{FT-IR Analysis}

The FT-IR spectrum of the grown crystal was recorded within the frequency region $400-4000 \mathrm{~cm}^{-1}$ using Bruker: RFS 27 spectrometer. The recorded spectrum is shown in Figure 3. The presence of functional groups was identified and the band assignments are tabulated in Table 1.

\begin{tabular}{|c|c|}
\hline Wave number $\left(\mathrm{cm}^{-1}\right)$ & Assignments \\
\hline 3330 & asymmetric N-H stretching \\
\hline 3082 & asymmetric C-H stretching \\
\hline 2782 & symmetric C-H stretching vibration of methyl group \\
\hline 1966 & overtones and combinations \\
\hline 1638 & $\mathrm{C}=\mathrm{C}$ stretching due to the aromatic ring \\
\hline 1549 & asymmetric stretching of $\mathrm{NO}_{2}$ group \\
\hline 1494 & COO stretching \\
\hline 1442 & $-\mathrm{CH}_{3}$ asymmetric bending \\
\hline 1369 & - $\mathrm{CH}_{3}$ symmetric bending \\
\hline 1315 & symmetric stretching of $\mathrm{NO}_{2}$ group \\
\hline 1270 & C-O stretching \\
\hline 1233 & $\mathrm{~N}-\mathrm{H} . . . \mathrm{S}$ hydrogen bonding \\
\hline 1158 & C-H bending \\
\hline 1079 & $\mathrm{P}\left(\mathrm{NH}_{2}\right)$ \\
\hline 1051 & C-N stretching \\
\hline 1022 & $\mathrm{C}-\mathrm{H}$ bending (in plane) \\
\hline 963 & C-H bending \\
\hline 936 & C-H deformation \\
\hline 907 & C-NO ${ }_{2}$ stretching \\
\hline 894 & C-C-N symmetric stretching \\
\hline 827 & $\mathrm{NO}_{2}$ scissoring \\
\hline 794 & C-H bending (out of plane) \\
\hline 751 & $\mathrm{NO}_{2}$ wagging \\
\hline 698 & C-H bending (out of plane) \\
\hline 546 & $\mathrm{NO}_{2}$ rocking \\
\hline 522 & $\mathrm{NO}_{2}$ scissoring \\
\hline 506 & $\delta(\mathrm{N}-\mathrm{C}-\mathrm{S})$ \\
\hline
\end{tabular}




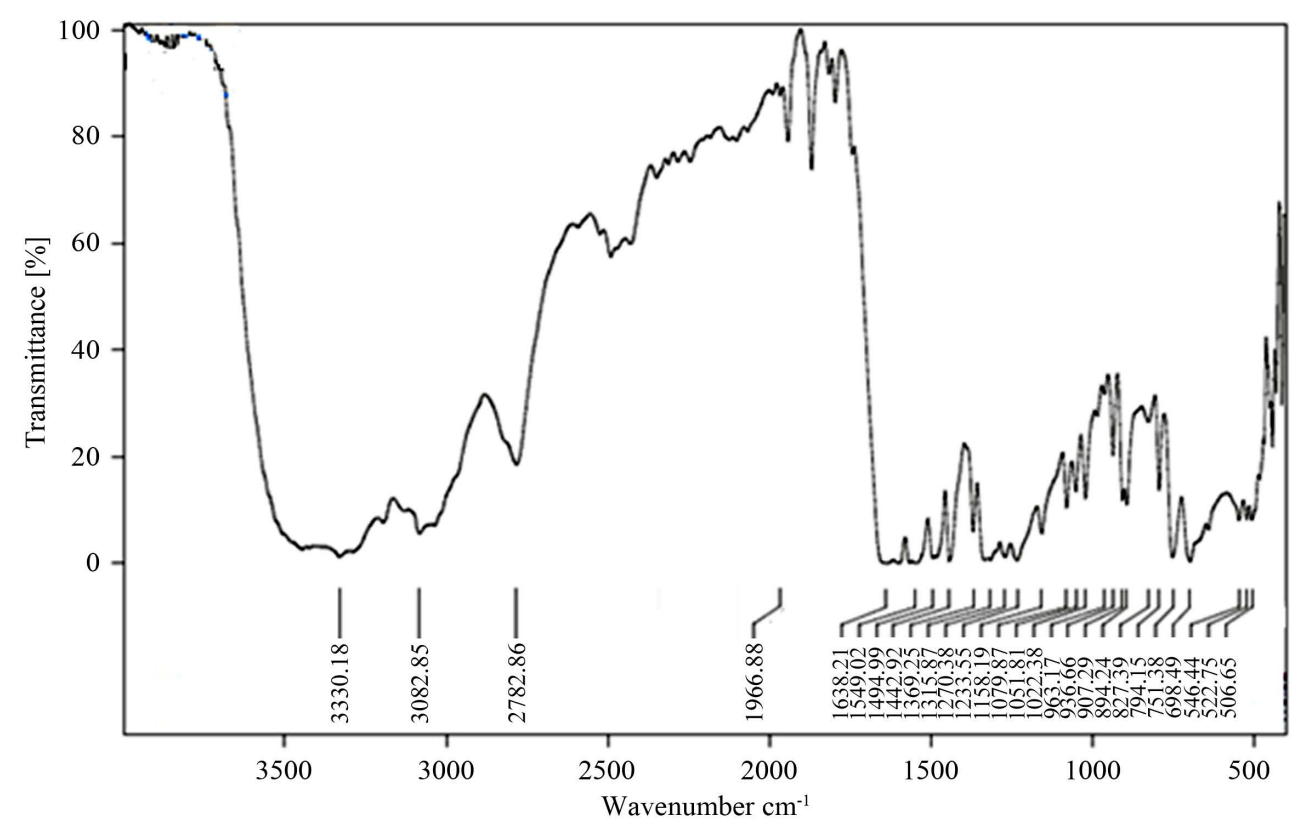

Figure 3. FT-IR spectrum.

\subsection{FT-Raman Analysis}

The recorded FT-Raman spectrum was shown in Figure 4.

The presence of functional groups was further confirmed by Raman spectrum. The peak at $3063.75 \mathrm{~cm}^{-1}$ is due to asymmetric stretching and the peak observed at $1646.24 \mathrm{~cm}^{-1}$ is due to C-C stretching. The strong peaks at $1328 \mathrm{~cm}^{-1}$ and $1308 \mathrm{~cm}^{-1}$ are due to symmetric stretching of $\mathrm{NO}_{2}$ group. The weak bands at $1269.31 \mathrm{~cm}^{-1}$ and $1155.78 \mathrm{~cm}^{-1}$ are due to C-O stretching and $\mathrm{C}-\mathrm{H}$ bending respectively. The C-N and C-NO${ }_{2}$ stretching bands are evidenced at $1051.85 \mathrm{~cm}^{-1}$ and $913.64 \mathrm{~cm}^{-1}$. $\mathrm{NO}_{2}$ scissoring is observed at $823 \mathrm{~cm}^{-1}$.

\subsection{UV-Vis Studies}

The absorption spectrum of the grown crystals was measured by double beam UV-Vis spectrophotometer for the wavelength range 200 to $800 \mathrm{~nm}$ and is shown in Figure 5.

The absorption spectrum plays a vital role in the fabrication of devices. It is observed that there is no remarkable absorption in the visible region and the lower cut off wavelength is $450 \mathrm{~nm}$. The absence of absorption above $450 \mathrm{~nm}$ is an advantage, as it is the prime requirement for materials having NLO properties. It can be used as an SHG material in the visible region.

\subsection{Thermogravimetric and Differential Scanning Calorimetric Studies}

TGA and DSC thermograms are recorded using NETZSCH STA 409C instrument between room temperature and $700^{\circ} \mathrm{C}$ in nitrogen atmosphere. Simultaneously recorded TGA and DSC thermograms are shown in Figure 6.

The recorded thermogram gives information about the phase transition, water of crystallization and different stages of decomposition of the crystal. Since the decomposition temperature is beyond $100^{\circ} \mathrm{C}$, there is no evidence for entrapped water in the crystal lattice or any adsorbed water on the crystal surface. The endothermic peak observed at $145^{\circ} \mathrm{C}$ corresponds to the melting point of the crystal. The material is moisture free and is stable upto $145^{\circ} \mathrm{C}$. This is followed by two exothermic peaks at $229^{\circ} \mathrm{C}$ and $347^{\circ} \mathrm{C}$ which may be due to the decomposition and volatilization of the compound. The total decomposition of the crystal occurs at $748^{\circ} \mathrm{C}$ and a residual mass of $1.22 \%$ is obtained. From the TGA and DSC curves it is evidenced that the crystals are stable up to $145^{\circ} \mathrm{C}$ and can be used for device applications below this temperature. 


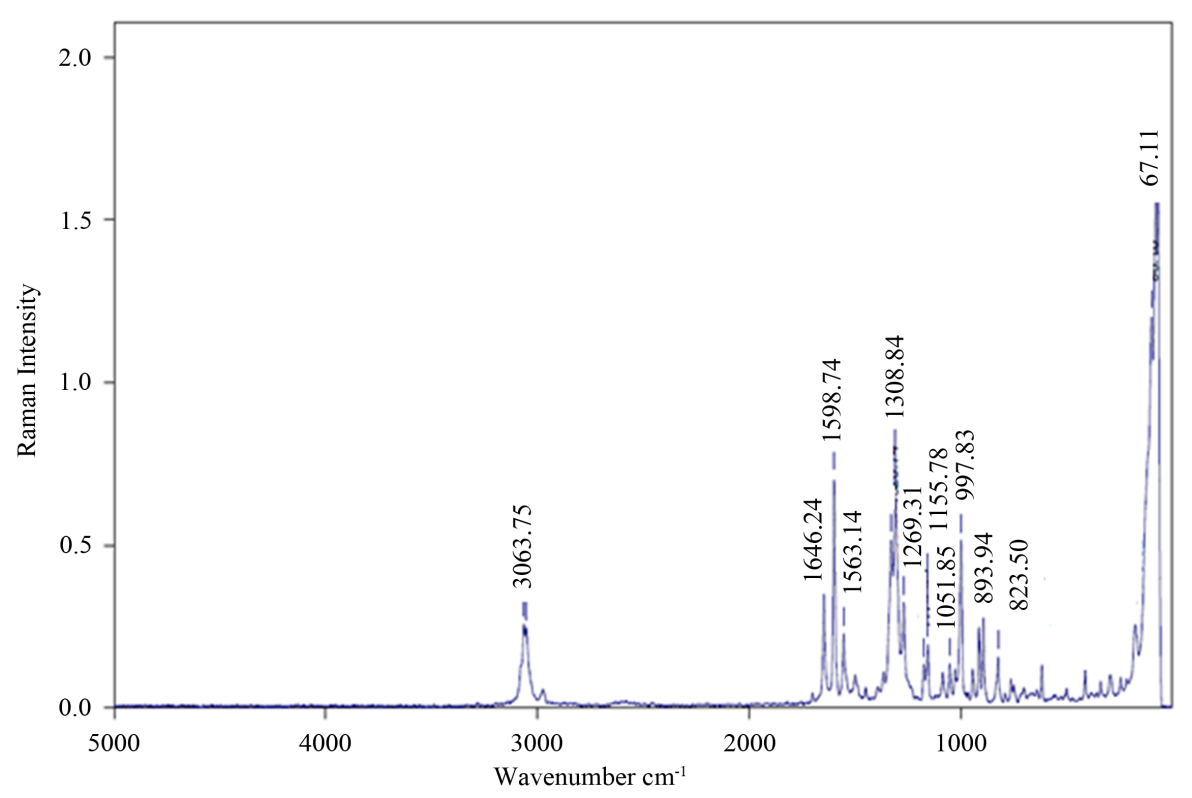

Figure 4. FT-Raman spectrum.

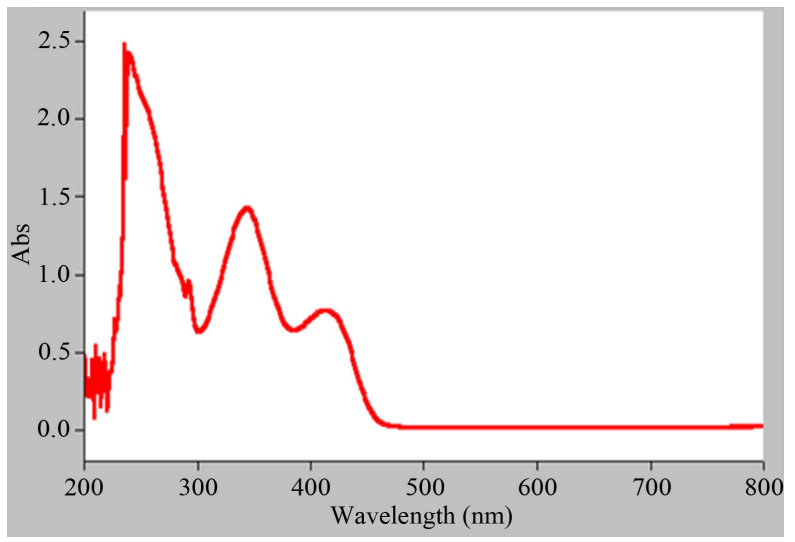

Figure 5. UV absorption spectrum.

\subsection{Non-Linear Optical Studies}

The SHG efficiency of the newly grown crystal is determined by Kurtz Perry powder test. The sample is powdered and is sandwiched between the two glass slides. A Q-switched Nd:YAG laser emitting a fundamental wavelength of $1064 \mathrm{~nm}$ and $8 \mathrm{~ns}$ pulse width, with $10 \mathrm{~Hz}$ pulse rate was focused on the glass slides. The frequency conversion efficiency of the crystal was confirmed by the emission of green radiation from the sample. Here the conversion efficiency of the material is compared with standard reference potassium di hydrogen phosphate (KDP) sample. The SHG efficiency of the crystal is found to be 0.64 times that the standard KDP crystal.

\section{Conclusion}

Single crystals of diphenyl urea were grown successfully by slow evaporation of the solvent at room temperature. Single crystal XRD confirms the formation of diphenyl urea crystal with a non-centrosymmetric space group of Pna2 $2_{1}$ with lattice parameters a $=9.11 \AA, b=10.56 \AA$, c $=11.78 \AA$. Vibration frequencies were assigned from FT-IR and FT RAMAN spectral analysis which confirms the presence of functional groups. Optical absorption studies show that the sample is optically transparent over a wide wavelength region and minimum absorption is observed in the entire visible region. From the thermal measurements it was found that the compound is stable up to $145^{\circ} \mathrm{C}$ and hence it may be useful for SHG applications below its melting point. The SHG 


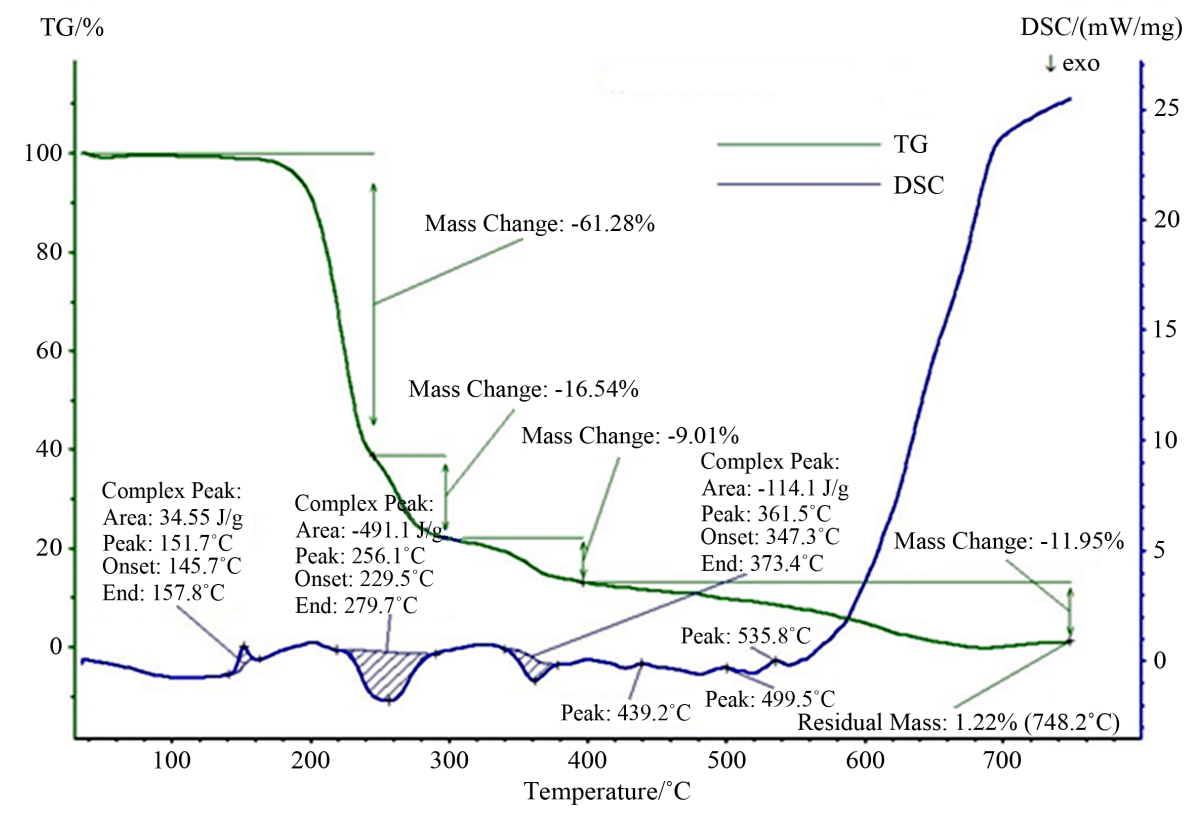

Figure 6. TGA \& DSC thermogram.

efficiency of the grown crystal was measured by Kurtz Perry powder test and its efficiency was found to be 0.64 times that of the standard KDP crystal. All the above strongly attributes diphenyl urea, a novel material for non linear optical applications.

\section{References}

[1] Lakshmana Perumal, C.K., Arulchakkaravarthi, A., Rajesh, N.P., Santhanaraghavan, P. and Ramasamy, P. (2002) Microhardness and Slip Systems of Solution Grown MHB Crystals. Materials Letters, 56, 578-586. http://dx.doi.org/10.1016/S0167-577X(02)00555-4

[2] Prasad, P.N. and Williams, D.J. (1991) Introduction to Nonlinear Optical Effects in Organic Molecules and Polymers. Wiley, New York.

[3] Chemla, D.S. and Zyss, J. (1987) Nonlinear Optical Properties of Organic Molecules and Crystals. Academic Press, New York.

[4] Bhowmik, A.K., Tan, S., Ahyi, A.C., Dharmadhikari, J.A., Dharmadhikari, A.K. and Mathur, D. (2007) Measurement of Ultrashort Laser Pulses Using Single-Crystal Films of 4-Aminobenzophenone. Optics Communications, 280, 472476.

[5] Iyanar, M., Thomas Joseph Prakash, J., Muthamizhchelva, C. and Ponnusamy, S. (2009) Synthesis, Growth and Characterization Studies of a Semiorganic Nonlinear Optical Single Crystal of Gamma Glycine. Journal of Physical Sciences, 13, 235-244.

[6] Chandramohan, A., Bharathikannan, R., Kandavelu, V., Chandrasekaran, J. and Kandhaswamy, M.A. (2008) Synthesis, Crystal Growth, Structural, Thermal and Optical Properties of Naphthalene Picrate an Organic NLO Material. Spectrochimica Acta Part A: Molecular and Biomolecular Spectroscopy, 71, 755-759. http://dx.doi.org/10.1016/j.saa.2008.01.036

[7] Rajinikant, Dinesh, Deshmukh, M.B. and Kamni (2006) Synthesis, X-Ray Structure and N-H...O Interactions in 1,3-d Iphenyl-Urea. Bulletin of Materials Science, 29, 239-242. http://dx.doi.org/10.1007/BF02706491 